\title{
Effect of salinity on oil production: review on low salinity waterflooding mechanisms and exploratory study on pipeline scaling
}

\author{
Tao Zhang ${ }^{1}$, Yiteng $\mathrm{Li}^{1}$, Chenguang $\mathrm{Li}^{2}$, and Shuyu Sun ${ }^{1, *}$ \\ ${ }^{1}$ Physical Science and Engineering Division, King Abdullah University of Science and Technology, 23955-6900 Thuwal, Saudi Arabia \\ ${ }^{2}$ China National Oil and Gas Exploration and Development Company Limited, 100034 Beijing, PR China
}

Received: 25 January 2020 / Accepted: 8 June 2020

\begin{abstract}
The past decades have witnessed a rapid development of enhanced oil recovery techniques, among which the effect of salinity has become a very attractive topic due to its significant advantages on environmental protection and economical benefits. Numerous studies have been reported focusing on analysis of the mechanisms behind low salinity waterflooding in order to better design the injected salinity under various working conditions and reservoir properties. However, the effect of injection salinity on pipeline scaling has not been widely studied, but this mechanism is important to gathering, transportation and storage for petroleum industry. In this paper, an exhaustive literature review is conducted to summarize several well-recognized and widely accepted mechanisms, including fine migration, wettability alteration, double layer expansion, and multicomponent ion exchange. These mechanisms can be correlated with each other, and certain combined effects may be defined as other mechanisms. In order to mathematically model and numerically describe the fluid behaviors in injection pipelines considering injection salinity, an exploratory phase-field model is presented to simulate the multiphase flow in injection pipeline where scale formation may take place. The effect of injection salinity is represented by the scaling tendency to describe the possibility of scale formation when the scaling species are attached to the scaled structure. It can be easily referred from the simulation result that flow and scaling conditions are significantly affected if a salinity-dependent scaling tendency is considered. Thus, this mechanism should be taken into account in the design of injection process if a sustainable exploitation technique is applied by using purified production water as injection fluid. Finally, remarks and suggestions are provided based on our extensive review and preliminary investigation, to help inspire the future discussions.
\end{abstract}

\section{Introduction}

Waterflooding is a commonly used approach to enhance oil recovery at the secondary recovery stage, mainly due to its cheaper and easier availability in various engineering environments [1-4]. Effects of salinity on interfacial tension during waterflooding have been noticed since the middle of 20 th century [5,6], and numbers of patents were granted for relevant techniques [7-9]. After the pioneering experiments in [10], the better performance of low salinity waterflooding has been recognized theoretically and this technique has become a preferred approach in Improved Oil Recovery (IOR) and Enhanced Oil Recovery (EOR) [11-20]. In order to figure out the dominant mechanisms that control the low salinity effect on oil recovery enhancement, numerous studies were conducted in both academia and industry, from laboratory core flooding tests [14] to field scale observations [21], from sandstone reservoirs [14] to carbonate reservoirs [22], from on-land oil fields [23] to

\footnotetext{
* Corresponding author: shuyu.sun@kaust.edu.sa
}

offshore fields [24], and from sole secondary EOR technique [25] to complex combined tertiary EOR technique [26].

Various mechanisms have been constantly proposed but there has never been a comprehensive mechanism that perfectly explains the recovery increase for all the practical cases. A number of popular mechanisms have been concluded in Table 1 with the corresponding publications in this year (2019) and recent five years (2015-2019) as the popularity index. The number of publications is counted from Google Scholar because there are some important and high-citation literature published in conferences, patents and technique reports, which may not be recorded in other resources. It should be noted that one mechanism may be considered as a special case of a more general and well-known mechanism. For example, the limited release of mixed-wet particles is listed as one mechanism in [27], but generally it can be categorized into the class of fine migration in Table 1. In [28], the wettability alteration is divided into the alteration mechanism from oil-wet to water-wet and from water-wet to oil-wet, but in our table they belong to the same category. Correlations can always 
Table 1. Mechanisms to explain the low salinity effect.

\begin{tabular}{lccc}
\hline Mechanism & Publications from 2015 & Publications from 2019 & Reference \\
\hline Fine migration & 252 & 56 & {$[109]$} \\
Wettability alteration & 2680 & 619 & {$[91]$} \\
Double layer expansion & 386 & 105 & {$[110]$} \\
Multicomponent ion exchange & 155 & 34 & {$[111]$} \\
Emulsification & 1440 & 302 & {$[112]$} \\
Mineral dissolution & 1080 & 204 & {$[109]$} \\
Saponification & 230 & 46 & {$[53]$} \\
Salt-in effect & 32 & 7 & {$[53]$} \\
Salt-out effect & 12 & 0 & {$[113]$} \\
pH & 255 & 52 & {$[83]$} \\
Pressure & 256 & 44 & {$[114]$} \\
Temperature & 765 & 142 & {$[115]$} \\
Viscosity & 77 & 14 & {$[116]$} \\
Salinity shock & 72 & 10 & {$[21]$} \\
\hline
\end{tabular}

be found in these mechanisms, between fine migration and mineral dissolution, between mineral dissolution and higher viscosity, between saponification and $\mathrm{pH}$ effect, and so forth. Interfacial tension can be reduced by a variety of factors, such as $\mathrm{pH}$ condition, mineral dissolution, emulsification and saponification, which are directly related with wettability alteration. This may explain why wettability is the most popular mechanism reported in publications, while the related ones are also frequently mentioned. A word cloud illustration is provided in Figure 1 to analyze the frequency of keywords and phrases appearing in a database consisting of 1000 selected publications with high citations and reliable resources. It is easy to find some popular terminologies, such as "recovery" (purpose of low salinity waterflooding), "wettability" (most recognized mechanism to control the effect), "carbonate" (reservoir rock type lacking thorough research), "surfactant" (another enhanced oil recovery technique combining with low salinity waterflooding in tertiary recovery).

Positive responses were obtained from laboratory experiments and field scale tests so that low salinity waterflooding has been extensively accepted and applied in petroleum industry. Relevant techniques have been developed by big oil companies all around the world and the representative ones are listed in Table 2 together with the corresponding project applications. Generally speaking, wettability alteration mechanism is taken into account in most of these techniques and the chemical interactions at the interface between oil/brine/rock system are the main focus. Thus, tertiary oil recovery methods, especially those that alter the wettability to a favorable manner including surfactant flooding and polymer flooding, have been incorporated with low salinity waterflooding technique. More studies and applications are performed on sandstone reservoirs than carbonate reservoirs. The presence of clay is often considered as the main reason since wettability alteration can be easier found and modeled in that case, while the heterogeneity of carbonate rock makes the interactions modeling

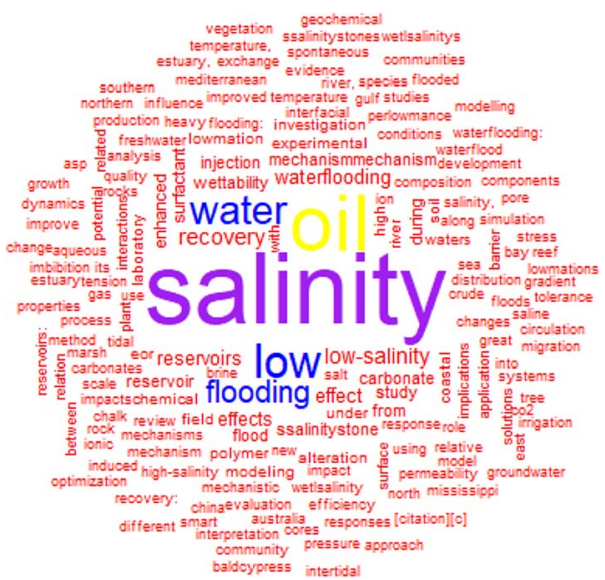

Fig. 1. A word cloud illustration on the research popularity of low salinity waterflooding.

at the interface more complicated [29]. The strong adsorption of carboxylic species on calcite surfaces makes the particle detaching so hard that high temperature is often needed to facilitate the multicomponent ion exchange. There are even studies which present a good performance of high salinity waterflooding, or just sea water injection, into carbonate reservoirs, especially chalk [30,31]. Spontaneous imbibition and forced displacement at high temperatures are considered to explain this increasing recovery [32]. However, positive effect of low salinity waterflooding has also been verified in carbonates by changing the capillary pressure curve in a favorable manner, which further improves oil recovery [33]. Generally, the following conditions are considered as needed to detect a significant low salinity effect: clay must exist in sandstone, polar components must exist in oil (like organic acids), divalent cations $\left(\mathrm{Ca}^{2+}\right.$ and $\left.\mathrm{Mg}^{2+}\right)$ must exist in the formation water. Other limitations on $\mathrm{pH}$, temperature, permeability conditions have all been resolved in recent publications. 
Table 2. Representative techniques to achieve low salinity waterflooding.

\begin{tabular}{lccc}
\hline Technique name & Oil company & Project applications & Reference \\
\hline LoSal & BP & Clair Ridge field & {$[15-17]$} \\
Smart waterflooding/smart water & Saudi Aramco & Shaybah field & {$[18-20]$} \\
Designer waterflooding & Shell & Omar field & {$[24,117,118]$} \\
Advanced ion management & Exxon & Hibernia field & {$[119,120]$} \\
\hline
\end{tabular}

The effect of fluid salinity on pipeline scaling is also observed in [34], in which the salinity of produced water from the Tuha Oilfield in Xinjiang, China is regarded as a key influence factor of pipeline scaling and inner corrosion. The correlation between the salinity of injected water and produced water is often considered to be positive and sometimes the produced water is injected back into the reservoir for recovery enhancement [35]. Thus, it is important to investigate the effect of injection salinity on pipeline scaling in the design of low salinity waterflooding process. Scaling tendency is often used as an index to evaluate the scaling property of oil/gas/water fluid flow in pipelines, and the index concept was first proposed in [36]. Afterwards, a stability index was proposed and a more comprehensive prediction equation has been derived to include more factors with proved better accuracy. Pipeline scaling is a serious problem often met in Middle East oil fields, for example, Halfaya oil field in Iraq. As one of Iraq's largest oil fields and the leading reconstruction projects after war, an enhanced oil production is urgently expected to rehabilitate the economy and stabilize the society. However, the lack of fresh water in this region results in an inevitable process of re-injecting production water or injecting purified sea water. Thus, the injection salinity should be carefully designed especially when salinity-related scaling has been reported in pipelines, heat exchangers and other facilities.

An exhaustive review is conducted in this paper, as well as an exploratory numerical investigation, to help readers new in this area to get a basic understanding on the effectivity and mechanisms of low salinity waterflooding, while experienced researchers and petroleum engineers are expected to be aware of the current research popularity and to be inspired by previous studies. The remainder of this paper is organized as follows. In Section 2, mechanisms in low salinity waterflooding will be analyzed from four well-recognized viewpoints: fine migration, wettability alteration, double layer expansion and multicomponent ion exchange. Correlations between the mechanisms are introduced and effect of working conditions including $\mathrm{pH}$, temperature, pressure and sample age are concluded afterwards. In order to mathematically describe the effect of salinity on pipeline scaling, numerical modeling is presented in Section 3 using phase-field model to describe the multi-phase fluid flow common seen in oil field, for the injection fluid mixture with purified produced water with certain species with scaling tendency. At the end, we make some conclusions in Section 4 and suggestions for further studies on this topic are provided based on the review in this paper.

\section{Mechanisms in low salinity waterflooding}

A thermodynamic equilibrium is always well established in the oil/formation water/rock system ahead of recovery processes like water injection. Human actions may break the millions of years' equilibrium and an optimal scheme is expected to maximize oil production with better economical performance. Mechanism analysis is necessary for this goal and practical techniques will be developed based on these mechanisms. In this section, we will start from the most intuitive phenomenon observed from a low salinity waterflooding experiment, fine migration, and then focus on the most popular and recognized mechanisms, wettability alteration. A microscopic electro-chemical mechanism, i.e. the double layer expansion, is included to describe the detailed process of electrostatic interactions and related surface changes. Additional mechanism of the interactions as well as precipitation and transportation, named multicomponent ion exchange, is also reviewed and these mechanisms are correlated closely to shed light on the low salinity waterflooding process. Four working conditions, $\mathrm{pH}$, temperature, pressure, and sample age are considered in our review and the main focus lays on their effect onto the performance of the aforementioned mechanisms under various reservoir and recovery conditions.

\subsection{Fine migration}

When a fluid passes through the reservoir rock surface that either contains insufficient total cation concentration or is short of divalent cations like $\mathrm{Ca}^{2+}$ and $\mathrm{Mg}^{2+}$, fine migration will be chemically initiated due to failure to prevent clay from hydration and swelling. Critical flocculation concentration, which is a criterion to evaluate the ionic strength, is strongly dependent on the relative concentration of divalent cations. Clay and silt in the reservoir formation can be destabilized by a low-salinity injection fluid and the dispersed compositions may flow with the fluid through the preferred channel in fractures with higher flow conductivity. Incremental oil recovery was reported in $[6,37]$ as a result of increased variance accompanied with clay swelling and dispersion. Fresh water even outperforms a non-saline injection fluid in [37], and clay swelling is considered as the main cause leading to less space for oil in the pores. Moreover, another explanation is provided in [38] that the dispersed fine particles may block the flow channels and oil recovery will be enhanced in the process of establishing new channels. Permeability reduction caused by different salt compositions of injection fluid is investigated further in [39], and it can be referred from their results that 
permeability damage may result from adding certain salts into pure water. The capillary effect sometimes help fine migration to influence the oil recovery but this effect is doubted in [40]. Electrostatic interactions occur together with fine migration. Clay are initially hydrated to a certain degree with negative charge [41], and the rock surfaces are positively charged. Crude oil is electro-negative due to the carboxylate group ( $\mathrm{COO}-$ ) and formation brine is positively charged due to the cations. As a cation exchanger, clay and silt may reduce the electrostatic force and momentum balance can be used to describe the process of detachment from the rock and dispersion in the fluid [42]. The importance of fine migration is underlined by spontaneous imbibition experiment increasing oil recovery in different sandstone cores [43].

However, it is also reported in $[16,44,45]$ that fine migration has no contribution to low salinity waterflooding. Limited production of clay particles can be observed under reduced or full reservoir conditions but additional oil recovery can still be shown. The fine concentration can keep the same with gradually reduced injection salinity in these cases and formation damage or permeability damage is minimized. Furthermore, it is stated in [46] that low salinity effect cannot be observed but sand production is detected. Efforts have been paid to explain the failure of this mechanism and a general explanation is that the effect of fine migration varies with lithology and mineralogy. For example, non-swelling property is found in the kaolinite formation, as presented in [47], while the swelling capability of montmorillonite clay may cause different outcomes. Another reason is pointed out in [48] that the dispersed fines may reattach to other surrounding rock surfaces and the pore spaces will be plugged. Thus, less particles can be detected in the core floods and fine migration is limited. In [28], another question is arisen that if more water-wet is preferred in low salinity waterflooding, the differential pressure should decrease rather than increase so that fine migration cannot be seen as the sole mechanism controlling low salinity effect.

\subsection{Wettability alteration}

As the most popular and recognized mechanism controlling the effect of low salinity waterflooding [49], wettability alteration is extensively investigated to explain the changing containing capabilities of oil and water in porous media, which is directly relevant to the macroscopic relative permeability. Various mechanisms are sometimes considered as a result of wettability alteration, including fine migration, multicomponent ion exchange, interfacial tension reduction and mineral dissolution, and these mechanisms are the phenomena behind enhanced oil recovery. Contact angel is the general indicator to quantitatively measure and describe wettability. A widely accepted classification of contact angle is proposed in [50] that: water-wet: $0^{\circ} \rightarrow 75^{\circ}$, intermediate-wet or mixed wet: $75^{\circ} \rightarrow 115^{\circ}$ and oil wet: $115^{\circ} \rightarrow 180^{\circ}$. Using this criteria, the contact angle is observed to change from oil-wet $\left(158^{\circ}\right)$ to mixed-wet $\left(113^{\circ}\right)$ in [51] and from oil-wet $\left(140^{\circ}\right)$ to mixed-wet $\left(108^{\circ}\right)$ in [52] during low salinity water injected into tight carbonate reservoirs.

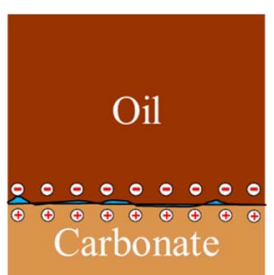

a

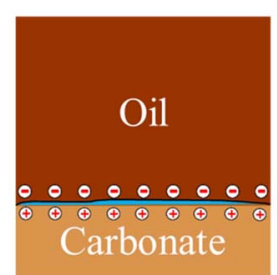

b

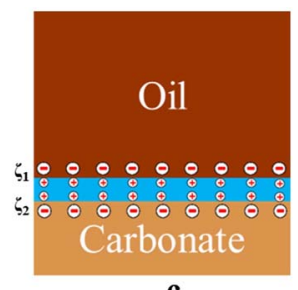

c
Fig. 2. A conceptual illustration of wettability alteration with thin film formation [58].

The effect of wettability alteration is found to be related with oil and brine compositions, rock and clay minerals and injection fluid salinity levels. For example, during low salinity water injection (1500 ppm) into sandstone, surfactantlike effect is observed after interactions with the reservoir rock and the oil-water interfacial tension is reduced with $\mathrm{pH}$ increasing up to 9 [53]. Thus, higher oil recovery is obtained while the wettability is altered from oil-wet to water-wet and more oil is released from the rock surface. Larger exposure on the rock surface to water may further enhance the imbibition through the film flow and increase the relative permeability. Core flooding tests in [47, 54] verify the lower residual oil saturations in porous media with mixed-wet conditions transferred from oil-wet or water-wet. Originally, the presence of clay is necessary to observe the alteration caused by fine migration and salt-in and salt-out effect [55], but recent studies have proposed other explanations including double layer expansion and calcite dissolution for carbonate reservoirs [22]. Wettability alteration is found to be possible for all the $\mathrm{pH}$ ranges [56], while the alteration trend may be different for higher and lower $\mathrm{pH}$ values. It is pointed out in [28] that $\mathrm{pH}$ is most likely to be under 9 for low salinity waterflooding cases, so that the most possible alteration direction is from water-wet to mixed-wet or intermediate-wet, which also explains the need of connate water in low salinity waterflooding to make water-wet possible.

Under general reservoir conditions, crude oil is negatively charged and carbonate rock is positively charged, which lead to the strong attachment of oil particles on rock surfaces and cause initial oil-wet conditions. Chemisorption mechanisms will increase the negative surface charge with the injection of low salinity fluids and then the repulsive part of disjoining pressure will enhance together with the wettability altered to water-wet. A thin film may appear in this process with the residual water on mineral surfaces [57]. A schematic representation of the process is illustrated in Figure 2 [58] and a double layer expansion mechanism is also involved. The thin film may provide a channel for imbibition phenomenon and flow conditions in reservoir will be improved thereby.

\subsection{Double layer expansion}

Derjaguin, Landau, Verwey, and Overbeek theory (DLVO theory), also known as the double layer theory, is often used to describe the electrostatic interactions which exhibit significant effects in low salinity waterflooding processes [48]. 


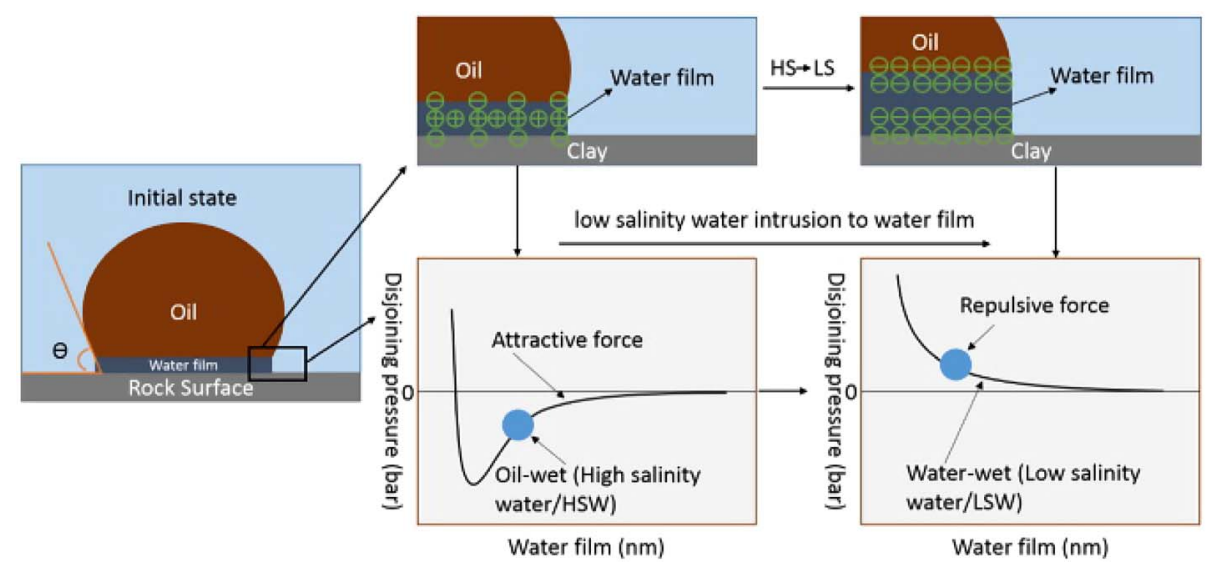

Fig. 3. A schematic illustration of the surface interactions in oil/brine/rock system with either high salinity water or low salinity water [123].

The classical theory models the disjoining pressure with two components: electrical force $\left(\Pi_{\mathrm{EDL}}(h)\right)$ and molecular force (or van der Waals force $\left.\Pi_{\mathrm{VDW}}(h)\right)$, and structural force $\left(\Pi_{\mathrm{STR}}(h)\right)$ is later added as a part of non-DLVO theory [59]. Van der Waals force in its loose sense (i.e., including all intermolecular forces) can be further divided into orientation force, induction force, and dispersion force; or respectively Keesom force, Debye force, and London dispersion force [60]. The preferential adsorption of potentialdetermining ions may occur through physical adsorption or chemical bonds, and the inner layer will be accumulated with adsorbed ions while the counter ions will form the second layer at the top. The electrical double layer force can be derived from the Coulombic interactions between a charged ion and a polar particle or between charged ions. The so-called electric double layer combines the effects of the electrostatic repulsion and van der Waals attraction. The clay-clay interaction is reduced with low salinity brine injection by the expansion of the double layer of counter ions and the repulsion is increased. The result of double layer expansion can be illustrated in Figure 3 to show the surface interaction in the oil/brine/rock systems with either high salinity water or low salinity water. The thin film between oil/brine and brine/rock is found to be more stable owing to this double layer expansion effect so that more oil can be detached from the rock surface and more water-wet conditions can be obtained [61]. Generally, the $\zeta$ - potential can be used to evaluate the film stability. A widely accepted criteria is $\pm 10 \mathrm{mV}$, and the film stability is assumed to increase with larger $\zeta$ - potential and film thickness, while the film is considered as unstable if $\zeta$ - potential is less than $\pm 10 \mathrm{mV}$ [62]. Similar mechanism was proposed in [13] to describe the process of mixed-wet particles releasing from the rock walls with the salinity reduction and double layer expansion, which results into locally heterogeneous wetting conditions and enhanced oil recovery.

Due to the molecular structure effect at the thin liquid film, especially the macro-molecules like polymers existing in the film, attentions on structural forces have been arisen in recent years to explain phenomena including colloid and polymer stability, while the classical DLVO theory fails
$[63,64]$. If hydrated cation adsorption occurs with hydrogen bonding network formed/broken or ion exchange induced, hydration force will appear and be recognized as primary or secondary force respectively $[65,66]$. Low salinity waterflooding is sometimes combined with surfactant assistant injection in tertiary oil recovery techniques to gather incremental oil recovery [67]. In that case, hydrophobic force may be generated as the rock and oil interface change from hydrophilic to hydrophobic [68]. Similarly, thermal fluctuations and chain bridging can be introduced with adsorption of polymers (injected in the low salinity water) onto suspended particles, and steric force or bridging force will be generated [64]. It should be stated that electrostatic interaction plays a role in almost every mechanisms of low salinity waterflooding, and the forces can be generated as a result of fine migration and multicomponent ion exchange.

\subsection{Multicomponent ion exchange}

Multicomponent Ion Exchange (MIE) mechanism demonstrates the effect of ion exchanges between surface-active components in the liquid and clay minerals [69-71]. The existence of divalent cations, such as $\mathrm{Ca}^{2+}$ and $\mathrm{Mg}^{2+}$, bridges the negatively charged clay surface and carboxylate material, eliminates the organic material at the surface, and enhances water wetness in this process. Repulsion between oil and clay surface is expected to occur and develop, which leads to oil molecules detaching from the rock surface and oil recovery increasing. Due to the difference in ion affinities on rock walls, MIE can result in the divalent cations strongly adsorbed on the surfaces until fully saturated. Before the low salinity waterflooding, the rock surfaces are more likely to be oil-wet due to the organo-metallic complexes formed by the multi-valent cations at solid surface and the polar compounds existing in the crude oils. The oil-wetness is enhanced by the direct adsorption of organic polar compounds in the crude oil onto the clay surface and replaces the labile cations at the surface. During the low salinity injection, such organic polar compounds will be removed and the organo-metallic complexes will be replaced 
Table 3. pH effect on wettability.

\begin{tabular}{lccc}
\hline $\mathrm{pH}$ change & Contact angle change & Reference & Citations \\
\hline $2.55 \rightarrow 4.42$ & $35^{\circ} \rightarrow 105^{\circ}$ & {$[75]$} & 12 \\
$3 \rightarrow 8$ & $48^{\circ} \rightarrow 175^{\circ}$ & {$[78]$, brine 1} & 15 \\
$3 \rightarrow 8$ & $30^{\circ} \rightarrow 54^{\circ}$ & {$[78]$, brine 2} & 15 \\
$2.55 \rightarrow 5.68$ & $35^{\circ} \rightarrow 175^{\circ}$ & {$[80]$} & 30 \\
$7 \rightarrow 5.3$ & $53^{\circ} \rightarrow 70^{\circ}$ & {$[121]$} & 86 \\
$3 \rightarrow 8$ & $24^{\circ} \rightarrow 64^{\circ}$ & {$[122], \mathrm{CaCl}_{2}$ brine } & 1 \\
$3 \rightarrow 8$ & $23^{\circ} \rightarrow 103^{\circ}$ & {$[122], \mathrm{Na}_{2} \mathrm{SO}_{4}$ brine } & 1 \\
\hline
\end{tabular}

with uncomplexed cations. It is noted in [14] that this process is meaningful under negligible precipitation of $\mathrm{Ca}^{2+}$ and $\mathrm{Mg}^{2+}$ salts, e.g. $\mathrm{Mg}(\mathrm{OH})_{2}$. More processes were proposed in [72] to explain the MIE mechanism, including cation exchange and bridging, ligand and water bridging, but the replacement of organic complexes with divalent cations and the bridging effect of divalent cations remain similar. The same mechanism was stated in [73] as polar compounds in crude oil, represented by resin and asphaltene, will form complexes by bonding to cations or adsorbed on clay.

\subsection{Effect of $\mathrm{pH}$}

As a fundamental role in controlling the surface chemistry for interactions on both oil/brine and brine/rock systems, $\mathrm{pH}$ condition has been extensively and deeply investigated in the low salinity waterflooding process. With the capability to describe the active ion exchange, $\mathrm{pH}$ is often used to identify other mechanisms including electrostatic interaction, double-layer expansion and clay migration. For example, clay dispersion is found to be minimized at low $\mathrm{pH}$ conditions and increasing $\mathrm{pH}$ is considered to amplify the fine releasing phenomenon from the rock wall and cause drastic permeability reduction [74]. Surface complexation modeling was performed in $[27,75-78]$ to quantitatively describe the effect of $\mathrm{pH}$ on wettability. Bond product sum, which is calculated by the summed products of the oppositely charged surface species locating on the brine/ mineral interface or the oil/brine interface, is introduced to indicate the wettability as a measurement of the oilmineral electrostatic attraction [76, 77]. Generally, more electrostatic bridges yield a greater bond product sum, which means that the system is more oil-wet [79]. It can be referred from their study that, wettability alterations can be influenced by $\mathrm{pH}$ conditions with the changing numbers of certain species at the oil/brine interface and brine/calcite interface with the presence of different compositions like $\mathrm{CaCl}_{2}$ and $\mathrm{Na}_{2} \mathrm{SO}_{4}$. It should be noted that the wettability alternation effect along with the increasing $\mathrm{pH}$ values may vary in different trends for flooding with different compositions. In Table 3, contact angle change with respect to the $\mathrm{pH}$ change in different injection conditions are concluded from previous literature. It is obvious that there remains a certain $\mathrm{pH}$ criterion that a strongly water-wet system could be triggered below it due to $\mathrm{H}^{+}$ adsorption at the interface and an opposite trend can be found in higher $\mathrm{pH}$ conditions. Furthermore, other factors including oil composition, rock type, ion type and ionic strength can play a secondary role in the surface condition alternation together with $\mathrm{pH}$. For example, an oil-wet system is found to be triggered by the conventional dilution approach at low $\mathrm{pH}$ conditions in carbonate type rocks, which can help explain the problem that low salinity effect is not always observed in the low salinity waterflooding into carbonate reservoirs [80]. Similarly, it can be predicted that water-wet system can be rendered in $\mathrm{CO}_{2}$ flooding or carbonated waterflooding due to the low $\mathrm{pH}$ conditions. In [81], larger disjoining pressure is needed for higher $\mathrm{pH}$ conditions in order to promote wettability alteration.

Another indicator to describe the effect of $\mathrm{pH}$ on surface conditions is electrokinetic potential, or simply as $\zeta$ - potential [82]. A strong dependence of $\mathrm{pH}$ on $\zeta$ - potential is demonstrated in [83], and the sensitivity is found to be higher in lower salinity injections. It can be concluded that the $\zeta$ - potential increases with increasing $\mathrm{pH}$ and this trend is generally suitable for all types of brine, which indicates that the surface charges shift to positive from the balance between positive and negative values with $\mathrm{pH}$ increasing. The strong chemical interactions varying with brine salinity at the interface is represented by the unfixed IEP value (isoelectric point), which is the $\mathrm{pH}$ at which no net electrical charge is carried on a molecule or the molecule can be viewed as electrically neutral in the statistical mean [84]. Larger range of $\mathrm{pH}$ values corresponding to negative $\zeta$ - potential can be detected by higher $\mathrm{pH}$ values of IEP with decreasing salinity, and it can be further referred that more oil recovery potential will be expected. However, opposite trend can be found in $[85,86]$ that $\zeta$ - potential may decrease with increasing $\mathrm{pH}$ values, which can be attributed to the difference in brine compositions. Indifferent ions in single-salt solutions used in certain experiments, including $\mathrm{Na}^{+}$and $\mathrm{K}^{+}$, are generally considered not to react with the carbonate surface, which results in the unaffected surface charge and therefore more negative $\zeta$ - potential with increasing $\mathrm{pH}$. Cation exchange is found to be enhanced with increasing $\mathrm{pH}$ at a given temperature condition [73]. Besides, larger electrostatic repulsion at the interface between rock and low salinity brine can be detected in higher $\mathrm{pH}$ conditions [87] and poorly negative charge at the oil-brine-rock interface will be resulted from decreasing $\mathrm{pH}$ [62], which means that both crude oil expulsion from surface and oil wetness are not favorable of small $\mathrm{pH}$ values. A simple explanation can be stated that higher $\mathrm{pH}$ can help 
release pre-existing organic material so that oil recovery is enhanced [88]. Thus, it can be concluded that a certain $\mathrm{pH}$ window is the best selection in practical engineering, and this range is suggested to be 5-6 in [48]. In [28], the author argued that $\mathrm{pH}$ cannot be used to confirm the low salinity waterflooding effect as $\mathrm{pH}$ is always measured to be lower than the emulsification or fine migration requirements in field tests and they believed that $\mathrm{pH}$ can either increase or decrease depending on other mechanisms.

\subsection{Effect of temperature}

Chemical understanding of low salinity waterflooding as an enhanced oil recovery technique often relies on the surface interactions and ion adsorptions, which are closely relevant to the temperature conditions. At the beginning, most low salinity waterflooding is conducted at lower temperatures $\left(<100{ }^{\circ} \mathrm{C}\right)$ [29], and no limitation in temperature is expected for effective enhanced oil recovery. However, high temperature low salinity waterflooding test in [89] suggested that low salinity effect may only be effective at higher temperatures $\left(>100{ }^{\circ} \mathrm{C}\right)$ with injection brine of lower salinity (no effect at salinity $=200000 \mathrm{ppm}$ and effective at salinity $=23000 \mathrm{ppm}$ ). Major mechanisms in low salinity waterflooding are affected by temperature, such as the decreasing adsorption of organic polar component with increasing temperature and increasing brine salinity. As the large quantities of crude oil found in high temperature reservoirs all around the world: the South China Sea, the Middle East and the Xinjiang Province in China, the chemical degradation effect at high temperature in tertiary oil recovery techniques like surfactant flooding and polymer flooding require bridging the gap of low salinity waterflooding studies at high temperatures as an alternative option for enhanced oil recovery.

A thorough investigation was performed in [27] to study the low salinity mechanism at high temperature (up to $140{ }^{\circ} \mathrm{C}$ ) on Tarim Field in western China. Water chemistry is found to control the surface interaction of oil/ brine/rock systems as a dominant role compared with temperature, so that low salinity waterflooding can be applied in reservoirs at high temperatures together with high acid number, which can be represented by AN $>2 \mathrm{mg} \mathrm{KOH} / \mathrm{g}$. The effect of temperature on wettability was studied in [27] using $\mathrm{CaCl}_{2}$ brine, which shows a different changing contact angle as temperature increases. Generally speaking, contact angle will increase more significantly with increasing temperature in high salinity brine injection. This phenomenon is more sensitive at higher $\mathrm{pH}$ conditions, but a limit will be found, above which the contact angle will remain the constant. Similar trend was found in [90] using different brine compositions $\left(\mathrm{Na}_{2} \mathrm{SO}_{4}\right)$, where temperature increase will cause contact angle increasing as well and the trend is affected by salinity and $\mathrm{pH}$ conditions. The effect of temperature reported in other literature are concluded in Table 4 and for all the cases we can see the similar trend.

\subsection{Effect of pressure}

Pressure is also found to influence the performance of low salinity waterflooding processes, and in most cases such effect is relevant to the wettability alteration mechanism [91, 92]. Results of contact angel measurements are concluded in Table 5 and it can be stated that the decrease of working pressure will always result in a decrease of the contact angle, indicating the wettability changing from oil-wet to water-wet. It should be noted that high pressure is often needed for heavy oil recovery, which requires a more careful design on the injection brine salinity.

\subsection{Effect of sample age}

The sample age has been considered as a factor affecting other mechanisms in recent years [75, 78]. It can be concluded from their results that contact angle will increase much faster in aged samples $\left(35^{\circ} \rightarrow 175^{\circ}\right)$ compared with un-aged ones $\left(30^{\circ} \rightarrow 81^{\circ}\right)$ under the same $\mathrm{pH}$ increasing conditions $(2.55 \rightarrow 5.68)$. Similar trend was found in [93] that oil recovery is enhanced in aged samples compared to un-aged samples with combination of low salinity waterflooding and surfactant flooding. In other word, the prevention effect of re-trapping of mobilized oil particles using surfactant and low salinity water is more obvious for aged samples.

\section{Numerical simulation on pipeline scaling with different injection salinity}

Numerical simulation is an effective approach to study mechanisms and phenomena especially when experimental studies are hard to perform [94-99]. Modeling the mechanisms behind low salinity waterflooding is the first step to mathematically understand and describe the observed phenomenon, as well as the key point in developing advanced enhanced oil recovery techniques. In this section, the effect of salinity on pipeline scaling is illustrated based on direct numerical simulation using phase-field models. The phase field model is a mathematical model to solve interfacial problems. It has been applied to solidification dynamics, viscous fingering, fracture dynamics, vesicle dynamics, etc. The method substitutes boundary conditions (matching conditions) at the interface by a partial differential equation for the evolution of an auxiliary field (the phase field) that acts as an order parameter [100-102]. A phase-field model is usually constructed in such a way that in the limit of an infinitesimal interface width (the so-called sharp interface limit), the correct interfacial dynamics are recovered. This approach permits to solve the problem by integrating a set of partial differential equations for the whole system, thus avoiding the explicit treatment of the boundary conditions at the interface. In other words, compared to the sharp interface method, including Level Set, VOF, and Front Tracking methods, the phase-field model is more capable to handle problems that concentrate the interface behaviors, like the scaling process in this study.

\subsection{Phase-field model}

In order to identify the regions occupied by the two fluids, we introduce a phase-field variable $\phi$ such that: 
Table 4. Temperature effect on wettability.

\begin{tabular}{lccc}
\hline Temperature change & Contact angle change & Reference & Citations \\
\hline $140^{\circ} \mathrm{F} \rightarrow 250^{\circ} \mathrm{F}$ & $46^{\circ} \rightarrow 64^{\circ}$ & {$[92]$, formation brine } & 68 \\
$1400^{\circ} \mathrm{F} \rightarrow 250^{\circ} \mathrm{F}$ & $53^{\circ} \rightarrow 74^{\circ}$ & [92], sea water & 68 \\
$140^{\circ} \mathrm{F} \rightarrow 250^{\circ} \mathrm{F}$ & $36^{\circ} \rightarrow 53^{\circ}$ & {$[92]$, aquifer water } & 68 \\
$25^{\circ} \mathrm{C} \rightarrow 100^{\circ} \mathrm{C}$ & $24^{\circ} \rightarrow 37^{\circ}$ & {$[122], \mathrm{CaCl}_{2}$ brine } & 1 \\
$25^{\circ} \mathrm{C} \rightarrow 100^{\circ} \mathrm{C}$ & $23^{\circ} \rightarrow 25^{\circ}$ & {$[122], \mathrm{Na}_{2} \mathrm{SO}_{4}$ brine } & 1 \\
$60^{\circ} \mathrm{C} \rightarrow 140^{\circ} \mathrm{C}$ & $53^{\circ} \rightarrow 63^{\circ}$ & {$[27]$, formation brine } & 36 \\
$60^{\circ} \mathrm{C} \rightarrow 140^{\circ} \mathrm{C}$ & $29^{\circ} \rightarrow 63^{\circ}$ & {$[27]$, low salinity brine } & 36 \\
\hline
\end{tabular}

Table 5. Pressure effect on wettability.

\begin{tabular}{lccc}
\hline Pressure change & Contact angle change & Reference & Citations \\
\hline $1000 \mathrm{psi} \rightarrow 500 \mathrm{psi}$ & $60^{\circ} \rightarrow 52^{\circ}$ & {$[92]$, formation brine } & 68 \\
$1000 \mathrm{psi} \rightarrow 500 \mathrm{psi}$ & $76^{\circ} \rightarrow 73^{\circ}$ & {$[92]$, sea water } & 68 \\
$1000 \mathrm{psi} \rightarrow 500 \mathrm{psi}$ & $49^{\circ} \rightarrow 42^{\circ}$ & {$[92]$, aquifer water } & 68 \\
$175 \mathrm{psi} \rightarrow 105 \mathrm{psi}$ & $120^{\circ} \rightarrow 87^{\circ}$ & {$[91]$} & 7 \\
\hline
\end{tabular}

$$
\phi(\mathbf{x}, t)=\left\{\begin{array}{cc}
1 & \text { fluid } 1 \\
-1 & \text { fluid } 2
\end{array}\right.
$$

The phase-field variable $\phi(\mathbf{x}, t)$ can be either 1 or -1 to indicate different bulk phases of the system, but a value between $(1,1)$ within the interface, modeled as a thin (but nonzerothickness) transient layer. The (free) energy of the system (considering only spatial variation, not time change for now) is $F(\phi)=F_{b}(\phi)+F_{\nabla}(\phi)$, where the bulk free energy $F_{b}(\phi)$ can be modeled by the double-well potential:

$$
\begin{aligned}
& F_{b}(\phi)=\int_{\Omega} f_{b}(\mathbf{x}) \mathrm{d} \mathbf{x}, \\
& f_{b}(\phi)=\frac{c_{b}}{4}\left(\phi^{2}-1\right)^{2} .
\end{aligned}
$$

The double-well potential above is straightforward: it is one of the simplest polynomial functions with two minimums, one at $\phi=1$ and another at $\phi=-1$ [103]. In the van der Waals-Cahn-Hilliard gradient theory, the interfacial free energy has a contribution from the gradient of phasefield variable. The gradient has zero contribution to the free energy in the bulk phases as the gradient is zero, but the gradient contribution is defined over the entire domain:

$$
F_{\nabla}(\phi)=\int_{\Omega} \frac{c_{I}}{2}|\nabla \phi|^{2} \mathrm{~d} \mathbf{x}
$$

where $c_{I}$ is a parameter in the model. The coefficient $c_{I}$ can be a function of $\phi$ in general, but we assume it a constant for simplicity. The free energy for the diffuse interface model now becomes:

$$
F=F_{b}+F_{\nabla}=\int_{\Omega}\left(\frac{c_{b}}{4}\left(\phi^{2}-1\right)^{2}+\frac{c_{I}}{2}|\nabla \phi|^{2}\right) \mathrm{d} \mathbf{x} .
$$

The Cahn-Hilliard equation (named after John W. Cahn and John E. Hilliard) is designed starting from the conservation law:

$$
\frac{\partial \phi}{\partial t}=-\nabla \cdot \mathbf{J}
$$

There are two properties desired for the $\mathbf{J}$ expression. First, the constitutive equation linking between $\mathbf{J}$ and $\phi$ is desired to have the decaying property of the free energy, according to the second law of thermodynamics. Moreover, for consistency, the constitutive equation should also give $\mathbf{J}=0$ at equilibrium when chemical potential, $\mu=$ const. A natural choice for the constitutive equation linking between $\mathbf{J}$ and $\phi$ that satisfies the above two desired properties is:

$$
\mathbf{J}(x)=-M \nabla \mu,
$$

where $\mu=\frac{\delta F}{\delta \phi}=c_{b}\left(\phi^{3}-\phi\right)-c_{I} \nabla^{2} \phi$ and $M$ is the mobility coefficient.

Theorem 1: The Cahn-Hilliard equation used in our algorithm is mass conservative and energy stable, which denotes:

There is no diffusive flux on the domain boundary in the phase separation process,

$$
\frac{\mathrm{d}\left(\int_{\Omega} \phi(\mathbf{x}, t) \mathrm{d} \mathbf{x}\right)}{\mathrm{d} t}=0,
$$

and the energy law for Cahn-Hilliard equation is consistent with the second law of thermodynamics,

$$
\frac{\partial F}{\partial t} \leq 0
$$


Proof.

$$
\begin{gathered}
\frac{\mathrm{d}\left(\int_{\Omega} \phi(\mathbf{x}, t) \mathrm{d} \mathbf{x}\right)}{\mathrm{d} t}=\int_{\Omega} \frac{\partial \phi}{\partial t} \mathrm{~d} \mathbf{x}=\int_{\partial \Omega} \mathbf{J} \cdot \mathbf{n} \mathrm{d} s=0, \\
\frac{\partial F}{\partial t}=\left\langle\frac{\partial \phi}{\partial t}, \frac{\delta F}{\delta \phi}\right\rangle=\left\langle\nabla \cdot\left(M \nabla \frac{\delta F}{\delta \phi}\right), \frac{\delta F}{\delta \phi}\right\rangle \\
=-\left\langle M \nabla \frac{\delta F}{\delta \phi}, \nabla \frac{\delta F}{\delta \phi}\right\rangle=-M\left\|\nabla \frac{\delta F}{\delta \phi}\right\|^{2}=-M\|\nabla \mu\|^{2} \leq 0 .
\end{gathered}
$$

\subsection{Navier-Stokes-Cahn-Hilliard framework}

Recall that pressure can be viewed as the surface force exerted by a fluid against the wall of a container. Pressure exists at every point within a volume of fluid. Pressure $p$ in a direction $\mathbf{n}$ is defined as $p:=-\sigma \cdot \mathbf{n} \cdot \mathbf{n}$. From Pascal's law, we know the stress tensor is isotropic (i.e., $\sigma_{i j}=-p \delta_{i j}$ ) in bulk phase regions of a two-phase system, but $\sigma_{i j}$ may be anisotropic in the transient layer of interface. We consider a Cahn-Hilliard fluid mixture system of two bulk phases separated by a planar interface perpendicular to the $x$ direction. We assume the interfacial spans from $x=L$ to $x=L$, and assume the system is static and at equilibrium. In the transient layer of the interface, the stress tensor $\sigma_{i j}$ may not be isotropic. Since the interface is planar and perpendicular to the $x=x_{1}$ direction, the interfacial tension must act on the $y=x_{2}$ and $z=x_{3}$ directions, but not on the $x$ direction, which induces anisotropy of stress tensor [104, 105].

We denote $p_{x}:=-\sigma_{x x}$ and $\tau_{i j}:=p_{x} \delta_{i j}+\sigma_{i j}$. Since the coordinates align with the principal directions, $\tau_{i j}$ is diagonal. It is clear that $\tau_{x x}=0$, but $\tau_{y y}$ and $\tau_{z z}$ are nonzero. $\tau_{y y}$ and $\tau_{z z}$ are related to the interfacial tension by:

$$
\begin{aligned}
& \gamma_{I, y}=\int_{-L}^{L} \tau_{y y} \mathrm{~d} x, \\
& \gamma_{I, z}=\int_{-L}^{L} \tau_{z z} \mathrm{~d} x .
\end{aligned}
$$

The interface tension can be derived as an analytic solution of the diffuse interface model as:

$$
\begin{aligned}
\gamma_{I}=F_{I} & =\int_{-\infty}^{\infty} c_{I}\left(\phi^{\prime}\right)^{2} \mathrm{~d} x=\int_{-\infty}^{\infty} c_{I} \phi^{\prime} \frac{1-\phi^{2}}{\sqrt{2} \zeta} \mathrm{d} x \\
& =\int_{-1}^{1} \sqrt{c_{b} c_{I}} \frac{1-\phi^{2}}{\sqrt{2}} \mathrm{~d} \phi=\frac{2 \sqrt{2}}{3} \sqrt{c_{b} c_{I}}
\end{aligned}
$$

and it is reasonable to assume that $\tau_{y y}=\tau_{z z}=c_{I}\left(\partial_{x} \phi\right)^{2}$.

Thus the expression for $\tau_{i j}$ is:

$$
\begin{aligned}
\tau & =c_{I}\left(\partial_{x} \phi\right)^{2}\left(\begin{array}{lll}
0 & 0 & 0 \\
0 & 1 & 0 \\
0 & 0 & 1
\end{array}\right) \\
& =c_{I}(\nabla \phi \cdot \nabla \phi) \mathbf{I}-c_{I}\left(\partial_{x} \phi\right)^{2}\left(\begin{array}{ccc}
1 & 0 & 0 \\
0 & 0 & 0 \\
0 & 0 & 0
\end{array}\right) \\
& =c_{I}(\nabla \phi \cdot \nabla \phi) \mathbf{I}-c_{I} \nabla \phi \otimes \nabla \phi,
\end{aligned}
$$

and the stress expression $\sigma=-p_{x} \mathbf{I}+\tau$ is transformed to:

$$
\sigma=\left(c_{I}(\nabla \phi \cdot \nabla \phi)-p_{x}\right) \mathbf{I}-c_{I} \nabla \phi \otimes \nabla \phi .
$$

The stress tensor can be split into an isotropic term and an anisotropic term:

$$
\begin{gathered}
\sigma=\sigma_{\text {iso }}+\sigma_{\text {aniso }}, \\
\sigma_{\text {iso }}=\left(c_{I}(\nabla \phi \cdot \nabla \phi)-p_{x}\right) \mathbf{I}, \\
\sigma_{\text {aniso }}=-c_{I} \nabla \phi \otimes \nabla \phi .
\end{gathered}
$$

The anisotropic part $\sigma_{\text {aniso }}$ results from the gradient contribution of free energy, and it can model the effect of interfacial tension to flow.

Recall Cauchy's equation of motion $\rho \frac{D v_{i}}{D t}=\rho g_{i}+\frac{\partial \sigma_{i j}}{\partial x_{j}}$, which can lead to the single-phase Navier-Stokes equation for incompressible fluid with constant shear viscosity:

$$
\rho\left(\frac{\partial \mathbf{v}}{\partial t}+\mathbf{v} \cdot \nabla \mathbf{v}\right)=\rho \mathbf{g}-\nabla p+\eta \nabla^{2} \mathbf{v}
$$

The above formulation does not contain the anisotropic term for modeling interfacial tension $\sigma_{\text {aniso }}$. By taking into account $\sigma_{\text {aniso }}$, we obtain the following (two-phase) Navier-Stokes equation:

$$
\rho\left(\frac{\partial \mathbf{v}}{\partial t}+\mathbf{v} \cdot \nabla \mathbf{v}\right)=\rho \mathbf{g}-\nabla p+\eta \nabla^{2} \mathbf{v}+\nabla \cdot \sigma_{\text {aniso }} .
$$

With $\sigma_{\text {aniso }}=-c_{I} \nabla \phi \otimes \nabla \phi$, the (two-phase) NavierStokes equation reads:

$$
\rho\left(\frac{\partial \mathbf{v}}{\partial t}+\mathbf{v} \cdot \nabla \mathbf{v}\right)=\rho \mathbf{g}-\nabla p+\eta \nabla^{2} \mathbf{v}-\nabla \cdot\left(c_{I} \nabla \phi \otimes \nabla \phi\right) .
$$

As we have the following mathematical identity:

$$
\nabla \cdot(\nabla \phi \otimes \nabla \phi)=\nabla \phi \nabla^{2} \phi+\nabla\left(\frac{\nabla \phi \cdot \nabla \phi}{2}\right),
$$

and we can absorb $\left(C_{I} \nabla \phi \cdot \nabla \phi / 2\right)$ to the pressure, the influence of the interfacial tension can also be written as

$$
\nabla \cdot \sigma_{\text {aniso }}=-c_{I} \nabla \phi \nabla^{2} \phi .
$$

Recall $\mu=\mu_{b}-c_{I} \nabla^{2} \phi$ and $\mu_{b} \nabla \phi=\nabla f_{b}$, implying $\mu \nabla \phi=$ $\nabla f_{b}-c_{I} \nabla \phi \nabla^{2} \phi$. Since we can absorb $f_{b}$ to the pressure, we also have:

$$
\nabla \cdot \sigma_{\text {aniso }}=\mu \nabla \phi .
$$

As a result, the (two-phase) Navier-Stokes equation reads:

$\rho\left(\frac{\partial \mathbf{v}}{\partial t}+(\mathbf{v} \cdot \nabla) \mathbf{v}\right)=\rho \mathbf{g}-\nabla p+\eta \nabla^{2} \mathbf{v}+\mu \nabla \phi, \quad$ in $\Omega$.

The volume conservation is still applicable as:

$$
\nabla \cdot \mathbf{v}=0, \quad \text { in } \Omega .
$$




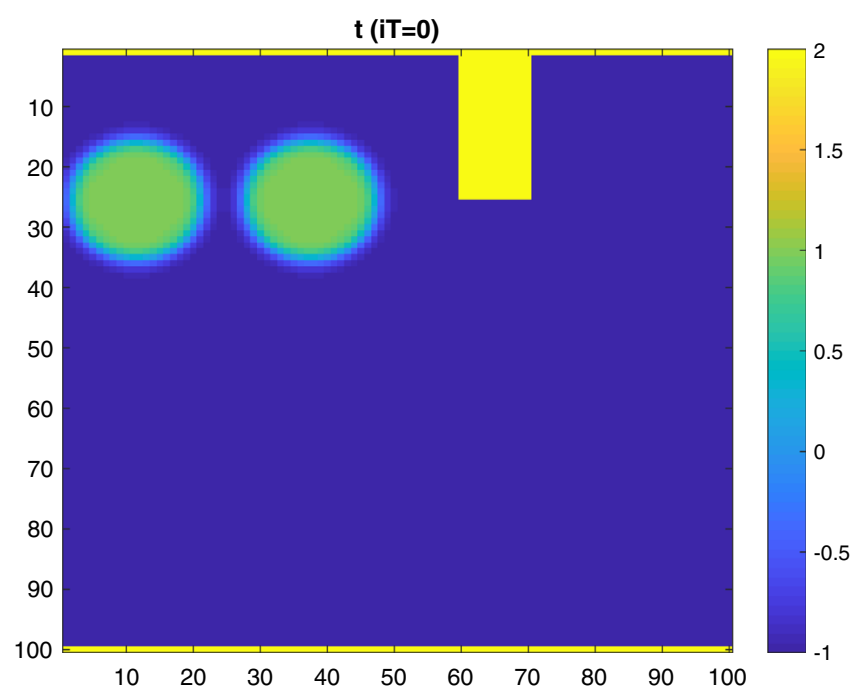

Fig. 4. Initial phase distribution of the injection fluid in pipelines with scaled structure.

The transport of interface is modeled by the Cahn-Hilliard equation (with convection):

$$
\frac{\partial \phi}{\partial t}+\mathbf{v} \cdot \nabla \phi=M \nabla^{2} \mu, \quad \text { in } \Omega
$$
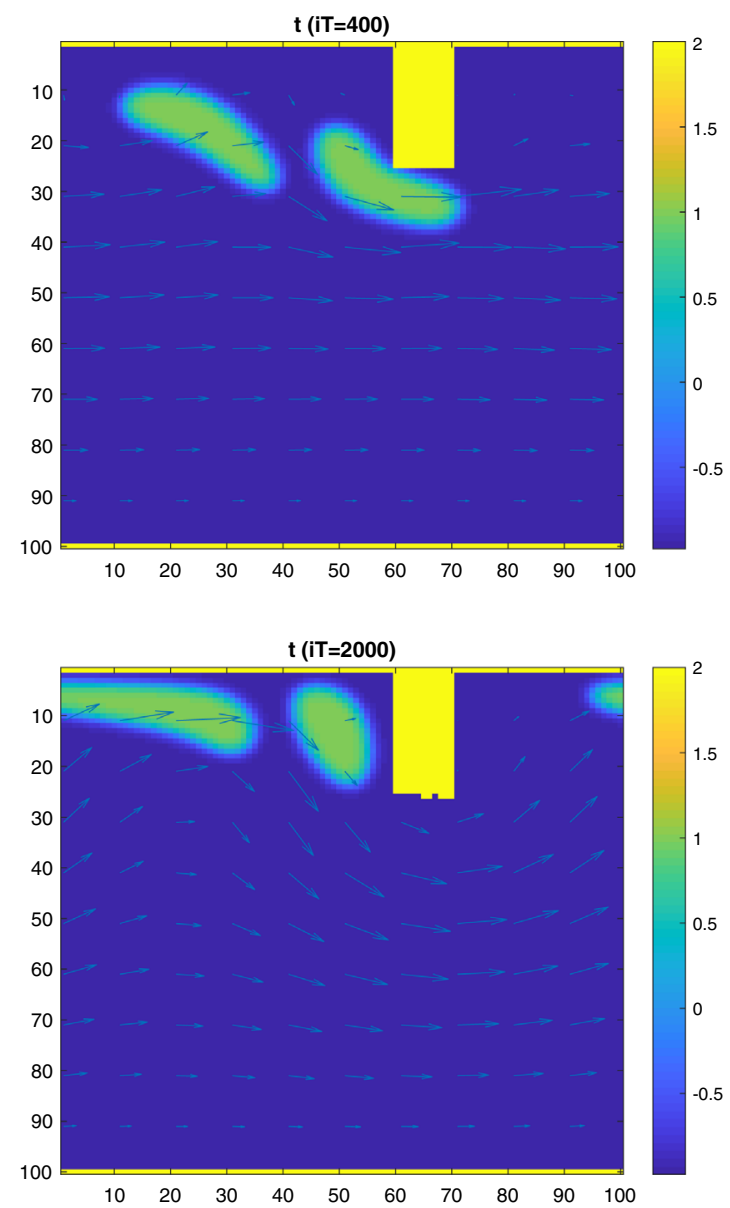

Finally, a comprehensive two-phase flow model is generated as coupling by equations (26)-(28). A fast algorithm for solving phase-field models is proposed in [106], constituted by an analytical solution as initial guess and an accelerated matrix solver, Shift-Matrix method [107]. This algorithm is also applied in this paper.

\subsection{Scaling simulation}

In this section, we will perform a direct numerical simulation on the flow and scaling process of injection fluid using produced water. We assume that there is certain scaled structure on the injection pipeline surface, and the injected water is polluted by some species with scaling tendency. As the mechanism of salinity on pipeline scaling has not been clearly described and mathematically modeled, a coefficient representing the scaling possibility is introduced in this paper to control the scaling process when certain species are attached on the scaled structure. Another assumption is that scaling is only considered in the vertical direction and a mass conservation restriction is added. In particular, the scaled species will be removed from the fluid mixture and no slip boundary condition is set on the scaled structure. Paraffin wax and asphalt are considered as the main species with scaling tendency in the injection fluid, and represented by the green droplets visualized in Figures $4-6$. The average
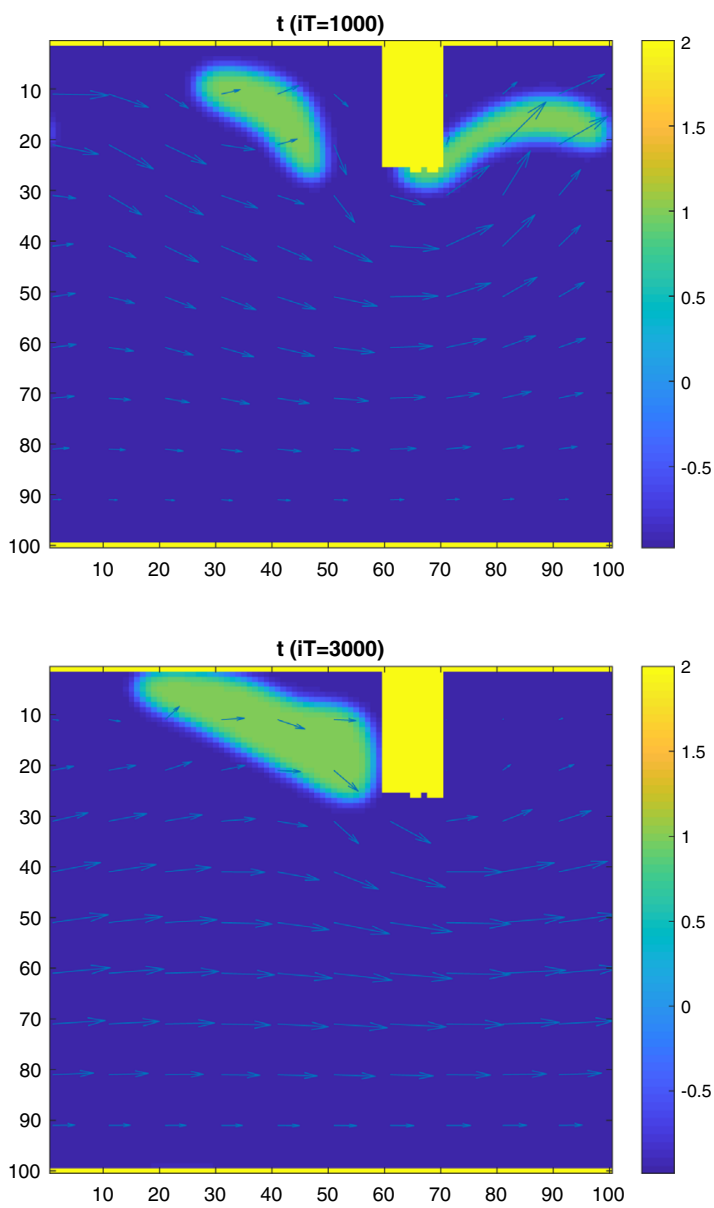

Fig. 5. Phase diagram in the flow and scaling process at different time steps with a small scaling tendency. 

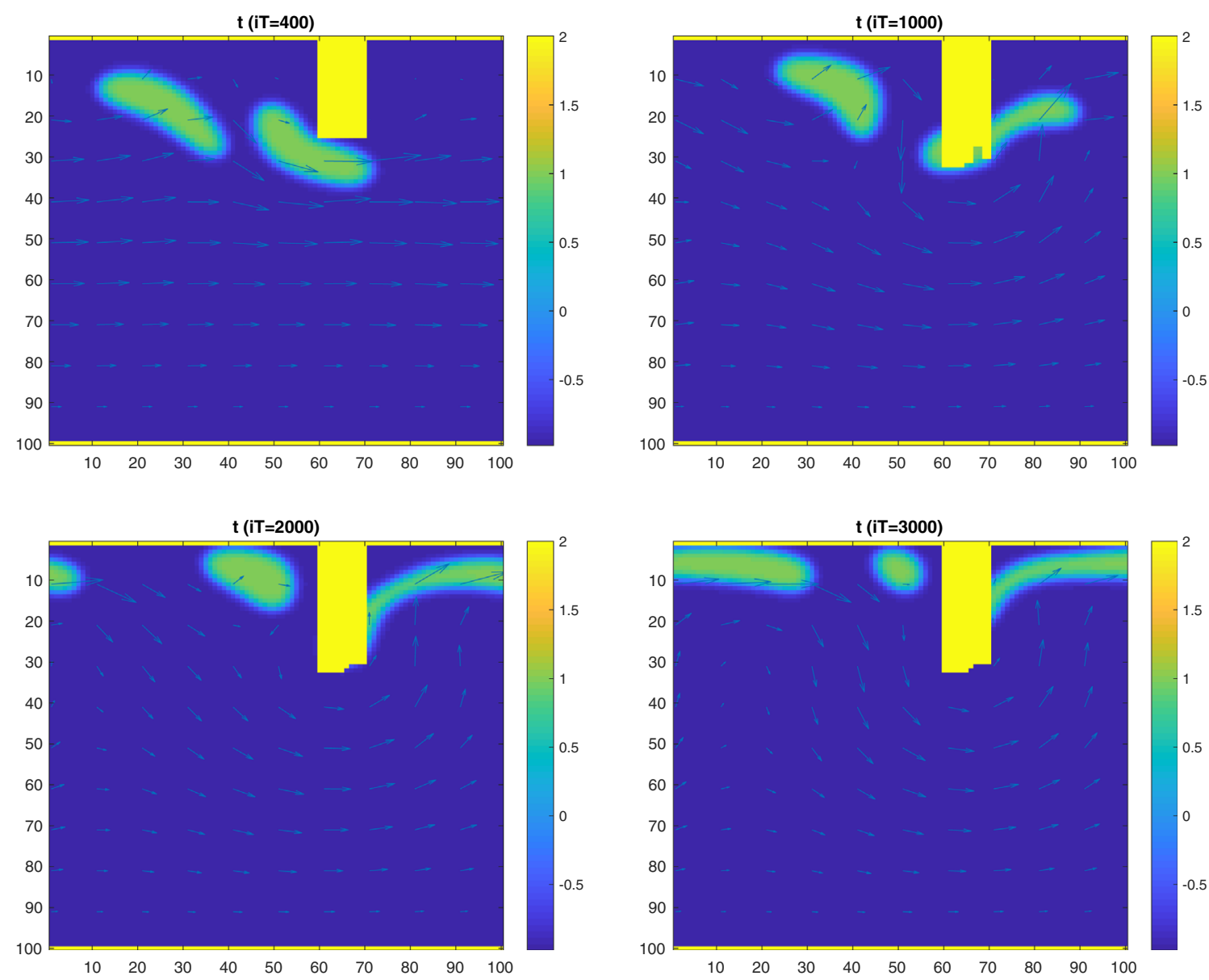

Fig. 6. Phase diagram in the flow and scaling process at different time steps with a large scaling tendency.

density of scaling species is set as $0.9 \times 10^{3} \mathrm{~kg} / \mathrm{m}^{3}$, while the density for injected water is set as $1.0 \times 10^{3} \mathrm{~kg} / \mathrm{m}^{3}$. At the beginning, two droplets of scaling species are placed near the left inlet, as shown in Figure 4, and the injection is from left to right. A scaled structure is placed near the right outlet and represented by yellow.

Two cases are designed to investigate the effect of salinity, represented by scaling tendency, on the fluid flow of injection water. A small scaling tendency is introduced in the case visualized in Figure 5 and a high tendency is introduced in Figure 6. Phase distribution at different time steps are provided and velocity quiver is added to show the injection. The yellow formation is growing with certain species scaled on the surface, while the flowing scaling species are decreasing in this process. A significant variation of scaling rate can be detected in these two cases, together with the difference on flow conditions in the domain. Scaling on pipeline inner surface is more serious in the case with higher scaling tendency, while the tackling on injection fluid flow is more significant. Due to the mass conservation property, the amount of certain species with higher scaling tendency are found to decrease in the injection together with the growing of scaled structure.

\section{Conclusion and remarks}

Low salinity waterflooding is becoming a favorable enhanced oil recovery technique due to its good performance on environmental protection, economic benefit and field implementation convenience. Various mechanisms have been proposed to explain the effectiveness and to simulate the flow and transport process in order to maximize oil recovery. In this paper, we go through the well-recognized and widely accepted mechanisms with details on the underlying physical and chemical processes, and mathematical models that describe these processes have been reviewed as well. It can be concluded that this technique has been successfully verified in both laboratory experiments and field test, and applied in practical engineering projects with various working conditions and reservoir properties. Wettability alteration is still the most recognized mechanism up to now, and other factors can always be related to it somehow. Therefore, other enhanced oil recovery techniques relevant with wettability and surface properties, including surfactant and polymer flooding, can be incorporated with low salinity waterflooding as a tertiary recovery technique. Multicomponent ion exchange and 
double layer expansion are effective approaches to model the microscopic interactions and the results can be used in macroscopic flow simulations via relative permeability and thermodynamic equilibrium conditions. There still remain certain cases with opposite results to our previous estimation, especially the effect of low salinity on carbonate rocks is challenging the development of a unified mechanism for all the rock types. Based on our review and understanding, following suggestions are recommended for future discussion:

1. A unified mechanism/theory/model is urgently needed to describe the mechanisms of low salinity waterflooding on both reservoir rock types: sandstone and carbonate. Studies on the carbonate reservoirs are much less than on sandstone reservoirs, and sometimes it fails to directly use the well-known mechanisms of sandstone reservoirs to explain the phenomenon in carbonate reservoirs. An interesting fact is that many oil fields in Middle East are carbonate type and water resources are difficult to obtain in this area. Thus, a decent, comprehensive and rigorous unified mechanism capable of explaining the favorable effect of low salinity waterflooding is a very attractive approach to convince oil companies using this technique and overcoming the difficulties of getting "smart water".

2. Machine Learning/Deep Learning algorithms are highly expected in accelerating the potential evaluation of using low salinity waterflooding technique. Numbers of factors are found relevant with the effect, and more complexity can come to our mind if we consider more components in the brine except for just calcium, magnesium and sodium. Ion exchange models are too complicated to compute, while Machine Learning can play a role in performing a reliable initial guess with the output of certain factors as input properties. More magic can be introduced if the many advanced Deep Neural Networks are applied in this area, which can also be used to accelerate the flow and transport simulation in the macroscopic description [108].

3. The design of injection salinity should take into consideration the effect on pipeline inner scaling. Such mechanism is seldom studied in previous research but the importance on gathering, transportation and storage process cannot be ignored in petroleum industry. A uniform and widely accepted model to mathematically describe the correlation between injection salinity and scaling tendency is hard to find currently, while most researches are focusing on establishing an empirical model suitable for certain produced water obtained from specific oil fields. As a result, a simple scaling possibility coefficient is proposed to describe the scaling tendency to semi-quantitative simulate the flow and scaling process of injection water. The scaling phenomenon is clearly exhibited and the discourage of scaling on flow is reasonable. General mass conservation is preserved in this study, as the scaling species in flow mixture are reduced in the process of scaling on the inner wall, but a more accurate analysis is expected if a clear mathematical scheme can be constructed. Thermodynamic stability and physical conservation properties will then be derived to make our simulation result reliable and applicable.

Acknowledgments. The research reported in this publication was supported by funding from King Abdullah University of Science and Technology (KAUST) through the grant BAS/1/ 1351-01-01.

\section{References}

1 Craig F.F. (1971) The reservoir engineering aspects of waterflooding, Henry L. Doherty Memorial Fund of AIME, New York.

2 Brouwer D.R., Jansen J.D. (2002) Dynamic optimization of water flooding with smart wells using optimal control theory, in: European Petroleum Conference, Society of Petroleum Engineers.

3 Holmgren C.R., Morse R.A. (1951) Effect of free gas saturation on oil recovery by water flooding, J. Pet. Technol. 3, 135-140.

4 Cooke C.E. Jr., Williams R.E., Kolodzie P.A. (1974) Oil recovery by alkaline waterflooding, J. Pet. Technol. 26, 1-365.

5 Dunlap P.M., Brandner C.F., Townsend H.L. (1969) U.S. Patent No. 3467190, U.S. Patent and Trademark Office, Washington, DC.

6 Martin J.C. (1959) The effects of clay on the displacement of heavy oil by water, in: Venezuelan Annual Meeting, Society of Petroleum Engineers.

7 Burdyn R.F., Chang H.L., Cook E.L. (1977) U.S. Patent No. 4004638, U.S. Patent and Trademark Office, Washington, DC.

8 Hurd B.G. (1983) U.S. Patent No. 4421168, U.S. Patent and Trademark Office, Washington, DC.

9 Hurd B.G. (1984) U.S. Patent No. 4463806, U.S. Patent and Trademark Office, Washington, DC.

10 Jadhunandan P.P., Morrow N.R. (1991) Spontaneous imbibition of water by crude oil/brine/rock systems, In Situ (United States) 15, 4.

11 Jadhunandan P.P., Morrow N.R. (1995) Effect of wettability on waterflood recovery for crude-oil/brine/rock systems, SPE Reserv. Eng. 10, 40-46.

12 Yildiz H.O., Morrow N.R. (1996) Effect of brine composition on recovery of Moutray crude oil by waterflooding, J. Pet. Sci. Eng. 14, 159-168.

13 Tang G.Q., Morrow N.R. (1999) Influence of brine composition and fines migration on crude oil/brine/rock interactions and oil recovery, J. Pet. Sci. Eng. 24, 99-111.

14 Austad T., RezaeiDoust A., Puntervold T. (2010) Chemical mechanism of low salinity water flooding in sandstone reservoirs, in: SPE Improved Oil Recovery Symposium, Society of Petroleum Engineers.

15 Robbana E., Buikema T.A., Mair C., Williams D., Mercer D.J., Webb K.J., Hewson A., Reddick C.E. (2012) Low salinity enhanced oil recovery-laboratory to day one field implementation-LoSal EOR into the Clair Ridge Project, in: Abu Dhabi International Petroleum Conference and Exhibition, Society of Petroleum Engineers.

16 Lager A., Webb K.J., Collins I.R., Richmond D.M. (2008) LoSal enhanced oil recovery: Evidence of enhanced oil recovery at the reservoir scale, in: SPE Symposium on Improved Oil Recovery, Society of Petroleum Engineers. 
17 Zekri A.Y., Nasr M.S., Al-Arabai Z.I. (2011) Effect of LoSal on wettability and oil recovery of carbonate and sandstone formation, in: International Petroleum Technology Conference, International Petroleum Technology Conference.

18 Salamy S.P., Al-Mubarak H.K., Hembling D.E., Al-Ghamdi M.S. (2006) Deployed Smart technologies enablers for improving well performance in tight reservoirs-case: Shaybah Field, Saudi Arabia, in: Intelligent Energy Conference and Exhibition, Society of Petroleum Engineers.

19 Yousef A.A., Liu J.S., Blanchard G.W., Al-Saleh S., Al-Zahrani T., Al-Zahrani R.M., Al-Tammar H.I., Al-Mulhim N. (2012) Smart waterflooding: Industry, in: SPE Annual Technical Conference and Exhibition, Society of Petroleum Engineers.

20 Yousef A.A., Al-Salehsalah S.H., Al-Jawfi M.S. (2011) New recovery method for carbonate reservoirs through tuning the injection water salinity: Smart waterflooding, in: $S P E$ EUROPEC/EAGE Annual Conference and Exhibition, Society of Petroleum Engineers.

21 Vledder P., Gonzalez I.E., Carrera Fonseca J.C., Wells T., Ligthelm D.J. (2010) Low salinity water flooding: Proof of wettability alteration on a field wide scale, in: $S P E$ Improved Oil Recovery Symposium, Society of Petroleum Engineers.

22 Zahid A., Shapiro A.A., Skauge A. (2012) Experimental studies of low salinity water flooding carbonate: A new promising approach, in: SPE EOR Conference at Oil and Gas West Asia, Society of Petroleum Engineers.

23 Seccombe J., Lager A., Jerauld G., Jhaveri B., Buikema T., Bassler S., Denis J., Webb K., Cockin A., Fueg E. (2010) Demonstration of low-salinity EOR at interwell scale, Endicott field, Alaska, in: SPE Improved Oil Recovery Symposium, Society of Petroleum Engineers.

24 Ayirala S.C., Uehara-Nagamine E., Matzakos A.N., Chin R.W., Doe P.H., van den Hoek P.J. (2010) A designer water process for offshore low salinity and polymer flooding applications, in: SPE Improved Oil Recovery Symposium, Society of Petroleum Engineers.

25 Ashraf A., Hadia N., Torsaeter O., Tweheyo M.T. (2010) Laboratory investigation of low salinity waterflooding as secondary recovery process: Effect of wettability, in: $S P E$ Oil and Gas India Conference and Exhibition, Society of Petroleum Engineers.

26 Mahani H., Sorop T., Ligthelm D.J., Brooks D., Vledder P., Mozahem F., Ali Y. (2011) Analysis of field responses to low-salinity waterflooding in secondary and tertiary mode in Syria, in: SPE Europec/EAGE Annual Conference and Exhibition, Society of Petroleum Engineers.

27 Xie Q., Brady P.V., Pooryousefy E., Zhou D., Liu Y., Saeedi A. (2017) The low salinity effect at high temperatures, Fuel 200, 419-426.

28 Sheng J.J. (2014) Critical review of low-salinity waterflooding, J. Pet. Sci. Eng. 120, 216-224.

29 Al-Shalabi E.W., Sepehrnoori K. (2016) A comprehensive review of low salinity/engineered water injections and their applications in sandstone and carbonate rocks, J. Pet. Sci. Eng. 139, 137-161.

30 Zhang P. (2006) Water-based EOR in fractured chalk wettability and chemical additives, $P h D$ Thesis, University of Stavanger, Norway, $125 \mathrm{p}$.

31 Hoegnesen E.J. (2005) EOR in fractured oil-wet chalk. Spontaneous imbibition of water by wettability alteration, PhD Thesis, University of Stavanger, Norway, 142 p.
32 Strand S., Puntervold T., Austad T. (2008) Effect of temperature on enhanced oil recovery from mixed-wet chalk cores by spontaneous imbibition and forced displacement using seawater, Energy Fuels 22, 3222-3225.

33 Webb K.J., Black C.J.J., Tjetland G. (2005) A laboratory study investigating methods for improving oil recovery in carbonates, in: International Petroleum Technology Conference, International Petroleum Technology Conference.

34 Liu X., Li J., Zhu Q., Feng J., Li Y., Sun J. (2009) The analysis and prediction of scale accumulation for waterinjection pipelines in the Daqing Oilfield, J. Pet. Sci. Eng. 66, 161-164.

35 Yousef A.A., Al-Saleh S.H., Al-Kaabi A., Al-Jawfi M.S. (2011) Laboratory investigation of the impact of injectionwater salinity and ionic content on oil recovery from carbonate reservoirs, SPE Reserv. Evalu. Eng. 14, 578-593.

36 Charles C.P. (1986) Applied water technology, Campbell Petroleum Series.

37 Bernard G.G. (1967) Effect of floodwater salinity on recovery of oil from cores containing clays, in: SPE California Regional Meeting, Society of Petroleum Engineers.

38 Alotaibi M.B., Nasr-El-Din H.A. (2009) Chemistry of injection water and its impact on oil recovery in carbonate and clastics formations, in: SPE International Symposium on Oilfield Chemistry, Society of Petroleum Engineers.

39 Merdhah A., Yassin A. (2009) Scale formation due to water injection in Berea sandstone cores, J. Appl. Sci. 9, 3298-3307.

40 Zeinijahromi A., Ahmetgareev V., Bedrikovetsky P. (2015) Case study of 25 years of low salinity water injection, in: SPE/IATMI Asia Pacific Oil $\&$ Gas Conference and Exhibition, Society of Petroleum Engineers.

41 Baptist O.C., Sweeney S.A. (1955) Effect of clays on the permeability of reservoir sands to various saline waters, US Department of the Interior, Bureau of Mines, Wyoming.

42 Akhmetgareev V., Khisamov R. (2015) 40 years of lowsalinity waterflooding in Pervomaiskoye Field, Russia: Incremental oil, in: SPE European Formation Damage Conference and Exhibition, Society of Petroleum Engineers.

43 Afekare D.A., Radonjic M. (2017) From mineral surfaces and coreflood experiments to reservoir implementations: Comprehensive review of low-salinity water flooding (LSWF), Energy Fuels 31, 13043-13062.

$44 \mathrm{Pu}$ H., Xie X., Yin P., Morrow N.R. (2010) Low-salinity waterflooding and mineral dissolution, in: SPE Annual Technical Conference and Exhibition, Society of Petroleum Engineers.

45 Zhang Y., Xie X., Morrow N.R. (2007) Waterflood performance by injection of brine with different salinity for reservoir cores, in: SPE Annual Technical Conference and Exhibition, Society of Petroleum Engineers.

46 Soraya B., Malick C., Philippe C., Bertin H.J., Hamon G. (2009) Oil recovery by low-salinity brine injection: laboratory results on outcrop and reservoir cores, in: SPE Annual Technical Conference and Exhibition, Society of Petroleum Engineers.

47 Morrow N.R. (1990) Wettability and its effect on oil recovery, J. Pet. Technol. 42, 1-476.

48 Brady P.V., Morrow N.R., Fogden A., Deniz V., Loahardjo N. (2015) Electrostatics and the low salinity effect in sandstone reservoirs, Energy Fuels 29, 666-677.

49 Morrow N., Buckley J. (2011) Improved oil recovery by lowsalinity waterflooding, J. Pet. Technol. 63, 106-112. 
50 Anderson W. (1986) Wettability literature survey-part 2: Wettability measurement, J. Pet. Technol. 38, 1-246.

51 Kafili Kasmaei A., Rao D.N. (2015) Is wettability alteration the main cause for enhanced recovery in low-salinity waterflooding? SPE Reserv. Evalu. Eng. 18, 228-235.

52 Alameri W., Teklu T.W., Graves R.M., Kazemi H., AlSumaiti A.M. (2015) Experimental and numerical modeling of low-salinity waterflood in a low permeability carbonate reservoir, in: SPE Western Regional Meeting, Society of Petroleum Engineers.

53 McGuire P.L., Chatham J.R., Paskvan F.K., Sommer D.M., Carini F.H. (2005) Low salinity oil recovery: An exciting new EOR opportunity for Alaska's North Slope, in: SPE Western Regional Meeting, Society of Petroleum Engineers.

54 Morrow N.R., Tang G.Q., Valat M., Xie X. (1998) Prospects of improved oil recovery related to wettability and brine composition, J. Pet. Sci. Eng. 20, 267-276.

55 RezaeiDoust A., Puntervold T., Strand S., Austad T. (2009) Smart water as wettability modifier in carbonate and sandstone: A discussion of similarities/differences in the chemical mechanisms, Energy Fuels 23, 4479-4485.

56 Drummond C., Israelachvili J. (2002) Surface forces and wettability, J. Pet. Sci. Eng. 33, 123-133.

57 Takamura K., Chow R.S. (1983) A mechanism for initiation of bitumen displacement from oil sand, J. Can. Pet. Technol. 22, 22-30.

58 Ding H., Rahman S. (2017) Experimental and theoretical study of wettability alteration during low salinity water flooding-an state of the art review, Colloids Surf. A Physicochem. Eng. Asp. 520, 622-639.

59 Derjaguin B.V., Churaev N.V. (1974) Structural component of disjoining pressure, J. Colloid Interface Sci. 49, 249-255.

60 Israelachvili J.N., Tabor D. (1972) The measurement of van der Waals dispersion forces in the range 1.5 to $130 \mathrm{~nm}$, Proc. R. Soc. London A. Math. Phys. Sci. 331, 19-38.

61 Ligthelm D.J., Gronsveld J., Hofman J., Brussee N., Marcelis F., van der Linde H. (2009) Novel waterflooding strategy by manipulation of injection brine composition, in: EUROPEC/EAGE Conference and Exhibition, Society of Petroleum Engineers.

62 Nasralla R.A., Nasr-El-Din H.A. (2014) Double-layer expansion: is it a primary mechanism of improved oil recovery by low-salinity waterflooding? SPE Reserv. Evalu. Eng. 17, 49-59.

63 Choudhary N., Nair A.K.N., Ruslan M.F.A.C., Sun S. (2019) Bulk and interfacial properties of decane in the presence of carbon dioxide, methane, and their mixture, Sci. Rep. 9, 19784.

64 Israelachvili J.N. (2011) Intermolecular and surface forces, Academic Press, Cambridge.

65 Pashley R.M. (1981) DLVO and hydration forces between mica surfaces in $\mathrm{Li}+, \mathrm{Na}+, \mathrm{K}+$, and $\mathrm{Cs}+$ electrolyte solutions: A correlation of double-layer and hydration forces with surface cation exchange properties, J. Colloid Interface Sci. 83, 531-546.

66 Chapel J.P. (1994) Electrolyte species dependent hydration forces between silica surfaces, Langmuir 10, 4237-4243.

67 Nourani M., Tichelkamp T., Gaweł B., Øye G. (2014) Method for determining the amount of crude oil desorbed from silica and aluminosilica surfaces upon exposure to combined low-salinity water and surfactant solutions, Energy Fuels 28, 1884-1889.
68 Horn R.G. (1990) Surface forces and their action in ceramic materials, J. Am. Ceram. Soc. 73, 1117-1135.

69 Fang C., Yang Y., Sun S., Qiao R. (2020) Low salinity effect on the recovery of oil trapped by nanopores: A molecular dynamics study, Fuel 261, 116443, 1.

70 Fang C., Sun S., Qiao R. (2019) Structure, thermodynamics, and dynamics of thin brine films in oil-brine-rock systems, Langmuir 35, 10341-10353.

71 Lager A., Webb K.J., Black C.J.J., Singleton M., Sorbie K.S. (2008) Low salinity oil recovery-an experimental investigation1, Petrophysics 49, 1-8.

72 Seccombe J.C., Lager A., Webb K.J., Jerauld G., Fueg E. (2008) Improving wateflood recovery: LoSalTM EOR field evaluation, in: SPE symposium on improved oil recovery, Society of Petroleum Engineers.

73 Sheng J.J. (2010) Modern chemical enhanced oil recovery: Theory and practice, Gulf Professional Publishing, Houston.

74 Valdya R.N., Fogler H.S. (1992) Fines migration and formation damage: influence of $\mathrm{pH}$ and ion exchange, $S P E$ Prod. Eng. 7, 325-330.

75 Sari A., Xie Q., Chen Y., Saeedi A., Pooryousefy E. (2017) Drivers of low salinity effect in carbonate reservoirs, Energy Fuels 31, 8951-8958.

76 Brady P.V., Krumhansl J.L., Mariner P.E. (2012) Surface complexation modeling for improved oil recovery, in: $S P E$ Improved Oil Recovery Symposium, Society of Petroleum Engineers.

77 Brady P.V., Thyne G. (2016) Functional wettability in carbonate reservoirs, Energy Fuels 30, 9217-9225.

78 Xie Q., Sari A., Pu W., Chen Y., Brady P.V., Al Maskari N., Saeedi A. (2018) pH effect on wettability of oil/ brine/carbonate system: Implications for low salinity water flooding, J. Pet. Sci. Eng. 168, 419-425.

79 Brady P.V., Krumhansl J.L. (2012) A surface complexation model of oil-brine-sandstone interfaces at $100{ }^{\circ} \mathrm{C}$ : Low salinity waterflooding, J. Pet. Sci. Eng. 81, 171-176.

80 Chen Y., Xie Q., Sari A., Brady P.V., Saeedi A. (2018) Oil/ water/rock wettability: Influencing factors and implications for low salinity water flooding in carbonate reservoirs, Fuel 215, 171-177.

81 Basu S., Sharma M.M. (1997) Investigating the role of crude-oil components on wettability alteration using atomic force microscopy, in: International Symposium on Oilfield Chemistry, Society of Petroleum Engineers.

82 Hunter R.J. (2013) Zeta potential in colloid science: Principles and applications, Academic Press, Cambridge.

83 Mahani H., Keya A.L., Berg S., Nasralla R. (2017) Electrokinetics of carbonate/brine interface in low-salinity waterflooding: Effect of brine salinity, composition, rock type, and $\mathrm{pH}$ on $\zeta$-potential and a surface-complexation model, SPE J. 22, 53-68.

84 Kosmulski M. (2000) Electrical interfacial layer in nonaqueous solvents, Interfacial dynamics, CRC Press, Boca Raton, pp. 289-328.

85 Hiorth A., Cathles L.M., Madland M.V. (2010) The impact of pore water chemistry on carbonate surface charge and oil wettability, Transp. Porous Media 85, 1-21.

86 Marouf R., Marouf-Khelifa K., Schott J., Khelifa A. (2009) Zeta potential study of thermally treated dolomite samples in electrolyte solutions, Micropor. Mesopor. Mater. 122, 99-104.

87 Omekeh A.V., Friis H.A., Fjelde I., Evje S. (2012) Modeling of ion-exchange and solubility in low salinity water flooding, 
in: SPE Improved Oil Recovery Symposium, Society of Petroleum Engineers.

88 Dang C.T., Nghiem L.X., Chen Z., Nguyen Q.P., Nguyen N.T. (2013) State-of-the art low salinity waterflooding for enhanced oil recovery, in: SPE Asia Pacific Oil and Gas Conference and Exhibition, Society of Petroleum Engineers.

89 Aghaeifar Z., Strand S., Austad T., Puntervold T., Aksulu H., Navratil K., Storås S., Håmsø D. (2015) Influence of formation water salinity/composition on the low-salinity enhanced oil recovery effect in high-temperature sandstone reservoirs, Energy Fuels 29, 4747-4754.

90 Alotaibi M.B., Azmy R., Nasr-El-Din H.A. (2010) Wettability challenges in carbonate reservoirs, in: SPE Improved Oil Recovery Symposium, Society of Petroleum Engineers.

91 Al-Saedi H.N., Flori R.E., Brady P.V. (2019) Effect of divalent cations in formation water on wettability alteration during low salinity water flooding in sandstone reservoirs: Oil recovery analyses, surface reactivity tests, contact angle, and spontaneous imbibition experiments, J. Mol. Liq. 275, 163-172.

92 Nasralla R.A., Bataweel M.A., Nasr-El-Din H.A. (2011) Investigation of wettability alteration by low salinity water, in: Offshore Europe, Society of Petroleum Engineers.

93 Alagic E., Spildo K., Skauge A., Solbakken J. (2011) Effect of crude oil ageing on low salinity and low salinity surfactant flooding, J. Pet. Sci. Eng. 78, 220-227.

94 Wang Y. (2019) Reynolds stress model for viscoelastic dragreducing flow induced by polymer solution, Polymers 11, 1659.

95 Wang Y., Sun S., Gong L., Yu B. (2018) A globally massconservative method for dual-continuum gas reservoir simulation, J. Nat. Gas Sci. Eng. 53, 301-316.

96 Wang Y., Sun S., Yu B. (2017) Acceleration of gas flow simulations in dual-continuum porous media based on the mass-conservation POD method, Energies 10, 1380.

97 Gong L., Xu Y.P., Ding B., Zhang Z.H., Huang Z.Q. (2020) Thermal management and structural parameters optimization of MCM-BGA 3D package model, Int. J. Therm. Sci. 147, 106120.

98 Li J., Zhang T., Sun S., Yu B. (2019) Numerical investigation of the POD reduced-order model for fast predictions of two-phase flows in porous media, Int. J. Numer. Method. Heat Fluid Flow 29, 4167-4204.

99 Zhang Tao, Sun Shuyu (2019) A coupled Lattice Boltzmann approach to simulate gas flow and transport in shale reservoirs with dynamic sorption, Fuel 246, 196-203.

100 Sun S. (2019) Darcy-scale phase equilibrium modeling with gravity and capillarity, J. Comput. Phys. 399, 108908, 22.

101 Kou J., Sun S., Wang X. (2020) A novel energy factorization approach for the diffuse-interface model with PengRobinson equation of state, SIAM J. Sci. Comput. 42, 1, B30-B56.

102 Zhu G., Kou J., Yao B., Wu Y.-S., Yao J., Sun S. (2019) Thermodynamically consistent modelling of two-phase flows with moving contact line and soluble surfactants, $J$. Fluid Mech. 879, 327-359.

103 Kou J., Sun S., Wang X. (2018) Linearly decoupled energy-stable numerical methods for multi-component two-phase compressible flow, SIAM J. Numer. Anal. 56, 6, 3219-3248.

104 Yang H., Sun S., Li Y., Yang C. (2019) A fully implicit constraint-preserving simulator for the black oil model of petroleum reservoirs, J. Comput. Phys. 396, 347-363.
105 Chen H., Kou J., Sun S., Zhang T. (2019) Fully massconservative IMPES schemes for incompressible two-phase flow in porous media, Comput. Methods Appl. Mech. Eng. 350, 641-663.

106 Zhang T., Sun S., Yu B. (2017) A fast algorithm to simulate droplet motions in oil/water two phase flow, Procedia Comput. Sci. 108, 1953-1962.

107 Zhang T., Salama A., Sun S., Zhong H. (2015) A compact numerical implementation for solving Stokes equations using matrix-vector operations, Procedia Comput. Sci. 51, 1208-1218.

108 Li Y., Zhang T., Sun S., Gao X. (2019) Accelerating flash calculation through deep learning methods, J. Comput. Phys. 394, 153-165.

109 Alhuraishawy A.K., Bai B., Wei M., Geng J., Pu J. (2018) Mineral dissolution and fine migration effect on oil recovery factor by low-salinity water flooding in low-permeability sandstone reservoir, Fuel 220, 898-907.

110 Xie Q., Liu F., Chen Y., Yang H., Saeedi A., Hossain M.M. (2019) Effect of electrical double layer and ion exchange on low salinity EOR in a $\mathrm{pH}$ controlled system, J. Pet. Sci. Eng. 174, 418-424.

111 Pouryousefy E., Xie Q., Saeedi A. (2016) Effect of multicomponent ions exchange on low salinity EOR: Coupled geochemical simulation study, Petroleum 2, 215-224.

112 Aldousary S., Kovscek A.R. (2019) The diffusion of water through oil contributes to spontaneous emulsification during low salinity waterflooding, J. Pet. Sci. Eng. 179, 606-614.

113 Lashkarbolooki M., Riazi M., Hajibagheri F., Ayatollahi S. (2016) Low salinity injection into asphaltenic-carbonate oil reservoir, mechanistical study, J. Mol. Liq. 216, 377-386.

114 Adekunle O., Tutuncu A.N. (2019) Comparative laboratory scale reservoir study on geomechanical property alterations arising from osmosis pressure distribution within Clay Rich Shales, in: Unconventional Resources Technology Conference, Society of Petroleum Engineers.

115 Torrijos I.D.P., Puntervold T., Strand S., Austad T., Tran V.V., Olsen K. (2017) Impact of temperature on the low salinity EOR effect for sandstone cores containing reactive plagioclase, J. Pet. Sci. Eng. 156, 102-109.

116 Buckley J.S., Morrow N.R. (2010) Improved oil recovery by low salinity waterflooding: A mechanistic review, in: 11th International Symposium on Evaluation of Wettability and its Effect on Oil Recovery.

117 Sorop T.G., Suijkerbuijk B.M.J.M., Masalmeh S.K., Looijer M.T., Parker A.R., Dindoruk D., Goodyear S. (2013) Accelerated deployment of low salinity waterflooding in Shell, in: IOR 2013-17th European Symposium on Improved Oil Recovery, European Association of Geoscientists \& Engineers.

118 Brooks D., Matzakos A., Ayirala S., Ligthelm D., Cense A. (2010) Designer Water ${ }^{T M}$ Flooding, in: 31st Annual Workshop and Symposium of the International Energy Agency (IEA) Collaborative Project on Enhanced Oil Recovery.

119 Gupta R., Smith G.G., Hu L., Willingham T., Lo Cascio M., Shyeh J.J., Harris C.R. (2011) Enhanced waterflood for carbonate reservoirs-impact of injection water composition, in: SPE Middle East Oil and Gas Show and Conference, Society of Petroleum Engineers.

120 Kaminsky R.D., Wattenbarger R.C., Szafranski R.C., Coutee A. (2007) Guidelines for polymer flooding evaluation and 
development, in: International Petroleum Technology Conference, International Petroleum Technology Conference.

121 Al-Attar H.H., Mahmoud M.Y., Zekri A.Y., Almehaideb R., Ghannam M. (2013) Low-salinity flooding in a selected carbonate reservoir: Experimental approach, J. Pet. Explor. Prod. Technol. 3, 139-149.
122 Sari A., Chen Y., Xie Q., Saeedi A. (2019) Low salinity water flooding in high acidic oil reservoirs: Impact of $\mathrm{pH}$ on wettability of carbonate reservoirs, J. Mol. Liq. 281, 444-450.

123 Xie Q., Saeedi A., Pooryousefy E., Liu Y. (2016) Extended DLVO-based estimates of surface force in low salinity water flooding, J. Mol. Liq. 221, 658-665. 